\title{
Preserving Rights for Individuals Facing Guardianship
}

\section{Citation}

Moye, Jennifer. 2011. “Preserving Rights for Individuals Facing Guardianship." JAMA 305 (9) (March 2): 936. doi:10.1001/jama.2011.247.

\section{Published Version}

10.1001/jama.2011.247

\section{Permanent link}

http://nrs.harvard.edu/urn-3:HUL.InstRepos:33444599

\section{Terms of Use}

This article was downloaded from Harvard University's DASH repository, and is made available under the terms and conditions applicable to Other Posted Material, as set forth at http:// nrs.harvard.edu/urn-3:HUL.InstRepos:dash.current.terms-of-use\#LAA

\section{Share Your Story}

The Harvard community has made this article openly available.

Please share how this access benefits you. Submit a story.

\section{Accessibility}




\section{Preserving Rights for Individuals Facing Guardianship}

Jennifer Moye, $\mathrm{PhD}$

Aanand D. Naik, MD

$\mathrm{T}$ He ISSUE OF ADUlT GUARDIANSHIP POSES INCREASing challenges in an aging society. Physicians play an essential role in ensuring its equitable and appropriate application. Yet physicians may be unaware of the evolution of guardianship law over the past 2 decades.

Physicians are knowledgeable about their older patients' functioning and such patients' experiences with elder abuse, neglect, or exploitation. As a result, physicians are identified to provide opinions regarding the capacity of their patients to live safely in the community or to manage health and financial affairs when a question of guardianship is raised. In most states, guardianship concerns the capacity to make personal decisions about health, home, and personal matters, and conservatorship concerns decisions about financial management. Guardianship and conservatorship are legal interventions by the state in which the rights to make decisions are removed from one person and assigned to another after a hearing. Reform of guardianship law throughout the United States places physician reports in a central evidentiary role for balancing individual rights with protections for older adults facing guardianship.

Requests to evaluate an older adult's capacity to live independently or manage personal finances occur in the context of dementia or other late-life degenerative illness, when a family member, neighbor, or agency pursues guardianship. ${ }^{1}$ This can create an ethical dilemma for the physician. Is this a patient whose neurological, psychiatric, and medical conditions have impaired decision making such that a finding of incapacity is warranted and a surrogate must assume decisional control? Or is this a patient whose independent decisions and lifestyle-sometimes fiercely guarded-must be supported?

\section{The Guardianship Reform Movement}

Guardianship reformers have called attention to limited due process protections to the vulnerable adult, such as inadequate notification of, legal representation for, and attendance at the hearing of the allegedly incapacitated person. Although usually well-meaning, guardianship may benefit the guardian more than the ward and hasten institutional-

936 JAMA, March 2, 2011 - Vol 305, No. 9 (Reprinted) ization for the protected person. Guardianship hearings are often brief, relying on incomplete or illegible $e^{2-4}$ information, and result in plenary appointments (judicial orders transferring all rights and powers to guardians). ${ }^{5}$

Beginning with a 1988 Associated Press investigative report documenting the problems with guardianship and fueled by ongoing concerns, the body of guardianship law has been substantially rewritten in the past 20 years. More than 272 bills have been voted into law across all 50 states, changing dramatically the procedures for guardianship appointment including substituting the term capacity for competency (to recognize that an individual may have varying strengths and weaknesses), encouraging the presence of the allegedly incapacitated person at the hearing, requiring functional evaluation by clinicians, and limiting the authority of the guardian to specific areas. ${ }^{6}$ In addition to these major reforms, minor reforms respond to changing needs. For example, in 2010 Minnesota required annual reports of criminal records of guardians, Wisconsin removed the rights of individuals under guardianship to possess firearms, and Maryland affirmed the rights of individuals under guardianship to vote if the individual communicates a desire to vote. In addition, 21 states have passed the Uniform Jurisdiction Act to resolve problems when individuals under guardianship move to different states for medical or financial reasons.

After 2 decades, the extent of legal reform is significant, but communication between courts and the medical community has been limited. Because of this, physicians may be unfamiliar with the guardianship reform movement as well as unclear about what information the courts need for the purposes of guardianship.

\section{Essential Elements of Capacity Evaluation}

The definition of an incapacitated person in the Uniform Guardianship and Protective Proceedings Act (UGPPA; a model act guiding guardianship reform) is "an individual ... unable to receive and evaluate information or make or communicate decisions to such an extent that the individual lacks the ability to meet essential requirements for physical health, safety, or self-care."7 In

Author Affiliations: VA Boston Healthcare System and Harvard Medical School, Boston, Massachusetts (Dr Moye); and Michael E. DeBakey VA Medical Center and Baylor College of Medicine, Houston, Texas (Dr Naik).

Corresponding Author: Jennifer Moye, PhD, Psychiatry, VA Boston Healthcare System and Harvard Medical School, Brockton Campus, 940 Belmont St, Brockton, MA 02301 (jennifer.moye@va.gov).

(C2011 American Medical Association. All rights reserved. 
response to requests by the legal and psychological communities for guidance on the assessment of capacity, the National College of Probate Judges, together with the American Bar Association and American Psychological Association, set out 6 elements essential for clinicians to provide the court in guardianship. ${ }^{8}$ These 6 elements of capacity evaluation are medical condition, cognition, everyday functioning, values, risks, and means to enhance capacity.

In brief, judges need to know what specific disorder is causing diminished capacity, typically a neurological or psychiatric condition, and to know if it is temporary and reversible vs permanent and degenerative. In addition to diagnoses, judges look for a description of how this condition affects the person's cognitive abilities, such as alertness, decision making, judgment, insight, and memory; and their everyday abilities, particularly instrumental activities of daily living, such as abilities to manage finances, health, and functioning in the home and community. The physician's report is also an opportunity to describe the person's values and preferences as well as incurred or imminent risks. For example, the physician may know that the patient has been financially meticulous and conservative (a value) but recently lost a large sum to an international lottery scheme (a risk). Information on both the values and risks assists in arriving at a fair decision that balances personal autonomy with protection. In addition, it is critical for the judge to know whether certain interventions may enhance capacity, such as hearing aids or antidepressant treatment, so the judge can accommodate the individual at the court and also review the guardianship appointment at a future date if the person's condition may improve.

A major change for the physician is the shift away from global declarations of competency based on diagnoses (eg, the individual is incompetent due to schizophrenia) to a more complex, functional definition (eg, the individual requires a conservator with limited authority to manage investments but not day-to-day spending). The opportunity to limit guardianship orders is one of the most important due process reforms of the past 20 years-with the physician's report providing key evidence to make such limitations possible.

\section{Training and Collaboration}

In contrast to health care consent capacity (eg, obtaining informed consent for surgery), physicians may feel less well prepared to evaluate capacity of functional tasks like managing finances, driving, or voting. To best prepare for com- pleting these more nuanced assessments for limited guardianship, physicians may seek additional training through continuing medical education, consult various models of capacity assessment, ${ }^{6,9,10}$ or identify appropriate consultants for behavioral or psychological assessment referral. ${ }^{6}$ Greater collaboration between the legal and health care communities is needed to bridge the gap between clinical assessments and the evidentiary needs of probate judges, to most effectively balance issues of autonomy and protection for older adults affected by neuropsychiatric illnesses.

Conflict of Interest Disclosures: All authors have completed and submitted the ICMJE Form for Disclosure of Potential Conflicts of Interest and none were reported.

Funding/Support: This Commentary is the result of work supported with resources and use of facilities at the Boston VA Medical Center and the Boston VA Research Institute for Dr Moye and by the Houston VA Health Services Research \& Development Center of Excellence (HFP90-020) at the Michael E. DeBakey VA Medical Center for Dr Naik. Dr Naik is also supported by National Institute on Aging Career Development Award K23AG027144 and by a Doris Duke Charitable Foundation Clinical Scientist Development Award.

Role of the Sponsors: The funding sources had no role in the preparation, review, or approval of the manuscript.

Additional Contributions: We appreciate the contributions of Neil Kowall, MD, VA Boston Healthcare System; Mark Kunik, MD, MPH, Michael E. DeBakey VA Medical Center; Mark Lachs, MD, MPH, Weill Cornell Medical College; James Rudolph, MD, SM, VA Boston Healthcare System; George Taffet, MD, Baylor College of Medicine; the American Bar Association and American Psychological Association Capacity Assessment of Older Adults Working Group; and the Texas Elder Abuse and Mistreatment Institute. No compensation was received.

\section{REFERENCES}

1. Moye J. Guardianship and conservatorship. In: Grisso T, ed. Evaluating Competencies. New York, NY: Plenum Publishers; 2003:309-390.

2. Bulcroft KA, Kielkopf MR, Tripp K. Elderly wards and their legal guardians: analysis of county probate records in Ohio and Washington. Gerontologist. 1991; 31(2):156-164.

3. Dudley KC, Goins RT. Guardianship capacity evaluations of older adults: comparing current practice to legal standards in two states. J Aging Soc Policy. 2003; 15(1):97-115.

4. Moye J, Wood S, Edelstein B, et al. Clinical evidence in guardianship of older adults is inadequate: findings from a tri-state study. Gerontologist. 2007;47 (5):604-612.

5. Lisi L, Burns A, Lussenden K. National Study of Guardianship Systems: Findings and Recommendations. Ann Arbor, MI: Center for Social Gerontology; 1994. 6. American Bar Association and American Psychological Association Assessment of Capacity in Older Adults Project Working Group. Assessment of Older Adults With Diminished Capacity: A Handbook for Psychologists. Washington, DC: American Bar Association and American Psychological Association; 2008.

7. National Conference of Commissioners on Uniform State Laws. Uniform Guardianship and Protective Proceedings Act (1997). http://www.law.upenn.edu/bll /ulc/fnact99/1990s/ugppa97.htm. Accessed December 29, 2006.

8. American Bar Association and American Psychological Association Assessment of Capacity in Older Adults Project Working Group. Judicial Determination of Capacity of Older Adults in Guardianship Proceedings: A Handbook for Judges. Washington, DC: American Bar Association and American Psychological Association; 2006.

9. Skelton F, Kunik ME, Regev T, Naik AD. Determining if an older adult can make and execute decisions to live safely at home: a capacity assessment and intervention model. Arch Gerontol Geriatr. 2010;50(3):300-305.

10. Moye J, Butz SW, Marson DC, Wood E; ABA-APA Capacity Assessment of Older Adults Working Group. A conceptual model and assessment template for capacity evaluation in adult guardianship. Gerontologist. 2007;47(5):591-603. 